\title{
Cuando la nación queda lejos: fronteras cotidianas en el paso Lago Verde (Aysén-Chile) - Aldea Las Pampas (Chubut-Argentina) ${ }^{1}$
}

\author{
Andrés Núñez², Brígida Baeza y Matthew C. Benwell ${ }^{4}$
}

\begin{abstract}
RESUMEN
Se busca reflexionar en torno a los procesos de colonialidad con que la nación va fijando el sentido de los espacios fronterizos y en cómo, en forma paralela y en diálogo a esa narración de escala nacional se desenvuelve un mundo cotidiano que muchas veces queda lejos de lo que es proyectado por la nación para esas particulares zonas. A través del caso de la zona fronteriza de Lago Verde-Las Pampas (Chile-Argentina) y de la presencia de una familia que ocupa desde "antes de la nación" toda el área fronteriza, ponemos en consideración "el despliegue de la experiencia del habitar", es decir, aquella "historicidad existencial" de los lugares o "estructura de la experiencia del territorio" que, en el fondo, restituye y proyecta una realidad intervenida por la memoria, por el arraigo a partir de aquella co-fabricación o co-pertenencia entre el sujeto y el paisaje que él mismo construye, al tiempo que lo habita (es decir, lo autoconstruye).
\end{abstract}

Palabras Claves: Frontera, cotidianidad, habitar, nación, experiencia vivida.

\begin{abstract}
This paper looks to reflect on the colonialist processes through which the nation determines a sense of its border spaces and how, at the same time and in dialogue with this national narrative, the everyday world of these border zones develops in ways that are often very different from what is projected by the nation. Through the case study of one border zone, that of Lake Verde-Las Pampas (Chile-Argentina), and the presence of a family that has occupied the entire border area from "before the nation", we consider evidence of the experience of living, or in other words, the existential historicity of place or the structure of territorial experience that, in essence, restores and projects a reality marked by memory; by roots based on co-production or co-belonging between the subject and the landscape that is constructed at the same time as it is inhabited (i.e. the landscape as self-constructed).
\end{abstract}

Keywords: Border, everyday, nation, lived experience.

El presente trabajo fue realizado gracias al apoyo de CONICYT (Chile) a través del proyecto FONDECYT № 1141169 y No 1170643 y del INTERNATIONAL PARTNERSHIP FUND, Newcastle University, UK. Artículo recibido el 10 septiembre de 2016, aceptado el 15 de noviembre 2017 y corregido el 30 de enero de 2017. Instituto de Geografía, Pontificia Universidad Católica de Chile (Chile). E-mail: aanunezg@uc.cl

CONICET, Universidad Nacional de la Patagonia San Juan Bosco (Argentina). E-mail: brigida_baeza@hotmail.com

School of Geography, Politics and Sociology, Newcastle University (Reino Unido). E-mail: matthew.benwell@newcastle.ac.uk 
"Somos todos parientes...los de allá y nosotros.

No mirábamos límites, mirábamos campos nomás"

(Habitantes de Lago Verde-Las Pampas, mayo 2014).

La nación ha sido narrada y producida desde una escala que involucra una dimensión amplia y uniforme y que nos remite a una supuesta e inevitable identidad común, una identidad que con el tiempo termina por "naturalizarse" y anclarse en una tradición inmóvil de la que pareciera no es posible moverse. Sabemos, sin embargo, que el surgimiento de una matriz interpretativa que actúa como organizadora del devenir de los habitantes de un territorio amplio llamado Nación nos remite a estrategias, dispositivos, desplazamientos metafóricos, narrativas sociales que en el fondo van organizando y fabricando un imaginario social homogéneo -la Patria, la Tradición, la Geografía, la Historia- que termina por invisibilizar prácticas que por ser mínimas o menores acaban instalándose en los márgenes de aquél discurso de escala nacional. En muchos casos, esas prácticas remiten a una cotidianidad que de modo silencioso construye horizontes y cosmovisiones que se desenvuelven lejos del poder hegemónico de alcance nacional.

En este contexto, este trabajo apunta a esa escala diferente, aunque no pierde de vista la relación de esta escala con la nacional/global. En efecto, se interesa en las prácticas y el quehacer cotidiano de una zona fronteriza que, en el fondo, representan una estructura de experiencia que está también cargada de "geograficidad" e "historicidad" (Dardel, 2013). Así, nos preguntamos ¿dónde quedan las diferencias culturales en ese proceso de racionalidad política de tipo nacional que define una identidad común? ¿dónde quedan las prácticas y el sentido del habitar de las distintas sociedades o culturas mínimas que implican y proyectan espacialidades cargadas de sentido, tan móviles y finitas como la propia dimensión de escala nacional?

Es indudable, como ya adelantamos, que esas escalas menores o locales no están ausentes de la narración nacional y se ven afectadas por las prácticas y discursos estatales e incluso influidos por componentes de tipo global. Este proceso de hibridez cultural que implica "un espacio-tiempo en movimiento, en constante fuga" (Núñez et al., 2017b), no inhibe otro asunto que es relevante para nuestra investigación y elemento central de lo que acá se expone: "el despliegue de la experiencia del habitar". Es decir, la relación del habitante con el habitar, del habitante con la morada de la existencia resulta vital, en tanto, precisamente, "la relación del hombre con los lugares y, por medio de los lugares, con los espacios, estriba en el habitar" (Heidegger, 1951). Aquella historicidad existencial de los lugares -o estructura de la experiencia del territorio como diría Giannini (1995)- restituye y proyecta la realidad intervenida -por la memoria, por el arraigo- a partir de aquella co-fabricación o co-pertenencia entre el sujeto y el paisaje que él mismo construye, al tiempo que lo habita (es decir, lo autoconstruye). Es un juego de producciones del sentido del lugar que deambula entre componer el lugar y ser admitido por el lugar en una co-pertenencia.

Interesa indagar y reflexionar sobre los procesos de producción social del territorio, en las experiencias construidas, no sólo desde las acciones, sino que también desde los silencios, las rupturas y las resistencias. En el fondo, desde la cotidianeidad y desde las prácticas que afianzan caminos culturales, imaginarios geográficos y memorias singulares, donde las preguntas y los argumentos sociales se configuran, en el fondo, como una centralidad en sí misma.

Desde este punto de vista, el espacio fronterizo de Lago Verde-Las Pampas situado al norte de la región de Aysén (Chile) y de la Provincia de Chubut (Argentina), lejos de ser un escenario 
estable, como el que se busca imaginar de manera tan abstracta como real para la nación, es una posibilidad o un mundo abierto donde prácticas del habitar dotan de significado particular a esa área fronteriza ${ }^{5}$. Particularmente interesante es esta zona, por cuanto remite a una memoria común de ambos lados del borde nacional. En efecto, hacia fines del siglo XIX y principios del XX como veremos, una familia -la familia Solís- se instala en lo que en ese momento eran valles sin dueños, aunque con un nomadismo indígena que no constituía propiedad privada (Núñez et al., 2016). Aproximadamente 40 años después, en 1936, aparece la Comisión de Límites y fija un borde estatal dejando al grupo familiar dividido entre "argentinos" y "chilenos". Si bien ellos se desplegaron en sus "campos" y en un ambiente rural dominante, los asentamientos de Las Pampas y Lago Verde, distantes a solo 10 kilómetros uno de otro, han representado hasta el día de hoy los íconos nacionales desde donde esos habitantes fronterizos se han ido narrando "un mundo", un mundo que los remite, por un lado, a las respectivas naciones y, por otro, al viaje cotidiano que desde sus prácticas les manifiesta que, en el fondo, a veces y muchas veces, "la nación les queda lejos" ${ }^{\text {. }}$

\section{Nación, territorio y producción de fronteras}

Aunque es su intención, la evidente finitud de la nación, en tanto sistema de significación cultural, le impide alcanzar una totalidad expresiva, por lo que su tarea es siempre mantener y actualizar las vías y las estrategias a través de las cuales pueda sostener la mirada en ese horizonte común, buscando dar fuerza a la ilusión de la identidad, como una suerte de "sueño homogéneo" (Bhabha, 2010).

En ello, la cultura nacional está en permanente contradicción y ambivalencia y afloran de manera permanente sus porosidades, sus fugas y sus miedos. Así, y esto es clave para comprender la narración de la nación, aquella cultura nacional "crea" y "define" espacios marginales, aislados o no incorporados como necesidad ineludible para sostener el discurso de la Modernidad o del Desarrollo y, por ende, la vigencia o la solidez del proyecto Nación? ${ }^{7}$. Es decir, existe, es o adquiere sentido en la medida que hayan "pendientes": "explorar" para el progreso, "incorporar" para la modernidad o "producir" mayor riqueza para volverse desarrollados, todos engranajes de un mismo panorama discursivo ${ }^{8}$.

Ese hilo teleológico es, en el fondo, su excusa. Bajo la misma lógica, la nación (re) constituye en forma permanente un ámbito internacional, un "otro" externo, para otorgar racionalidad a "lo nacional"9. De este modo, la producción y justificación de una frontera lineal y/o de espacios fron-

\footnotetext{
El año 2005 la Aldea las Pampas se la rebautizó como Comuna Rural Atilio Viglione, aunque la gente la sigue llamando Las Pampas.

En este artículo nos proponemos recuperar nuestros estudios acerca de la construcción de fronteras sociales en los procesos de "fronterización" binacional entre Chile y Argentina (Baeza, 2009; Núñez, 2013). Además, deseamos ofrecer aportes al estudio de casos de fronteras familiares/relacionales, donde "el centro" de las respectivas naciones más allá de sentirse (o no) impuestas, solapadas y reconocidas, poseen significancia los vínculos de vecindad y parentalidad al punto de constituirse en el centro de sus relaciones cotidianas. Poder registrar y analizar este proceso nos condujo al empleo de un tipo de experiencia metodológica cercana a la etnografía, con acercamientos fotográficos, de tomas de notas y realización de entrevistas en profundidad.

Para acercarse al tema de los discursos de la Modernidad, ver Quijano (2009) y Escobar (1998).

Benwell $(2014,2017)$ explora cómo se manifiesta estos discursos en las regiones polares como en el caso de la Antártica.

En un caso, expresará que lo "externo" o "internacional" es una imagen con la que la Nación debe dialogar e incluso imitar, como sucede por ejemplo, con los países europeos o Estados Unidos. En otro caso, será una amenaza con la que no hay que "tranzar", como se observa por ejemplo, con Bolivia (Núñez, 2014). Respecto del espacio como relación constante, dinámica, ver los estudios de la geógrafa inglesa Doreen Massey $(2005,2012)$.
} 
terizos se configura como una estrategia para dibujar el sentido hogareño que permite alimentar el sueño, el "mito" nacional1 ${ }^{10}$. En otras palabras, aquella "diferencia" es indispensable para afianzar esa pretendida identidad común: "La nación llena el vacío dejado por el desarraigo de las comunidades y las familias y transforma esa pérdida en el lenguaje de la metáfora. La metáfora transfiere el sentido del hogar y la pertenencia a través de distancias y diferencias culturales que separan la comunidad imaginada del pueblo-nación" (Bhabha, 2011: 176. El subrayado es nuestro).

Desde esta plataforma de comprensión, la nación -o los agentes que la han ido produciendofue consolidando hacia fines del siglo XIX y principios del XX el imaginario geográfico de una cordillera de Los Andes como límite "natural". Aquella construcción de una subjetividad fronteriza (Baeza, 2008, 2009, 2011) o producción de una matriz interpretativa de tipo fronterizo en torno a Los Andes, era fundamental para otorgar significancia a un amplio territorio. Desde esta perspectiva, esa producción era, en el fondo, en paralelo a la materialidad cordillerana de Los Andes, una construcción discursiva, es decir, una frontera discursiva (Núñez, et al., 2017a). Como ha expuesto Said: "A nosotros nos basta con establecer esas fronteras en nuestras mentes; así pues, ellos pasan a ser ellos y tanto su territorio como su mentalidad son clasificados diferentes de los nuestros [...] A las fronteras geográficas les siguen las sociales, étnicas y culturales de manera previsible" (2010: 87). Entonces, la sociedad estatal actúa bajo la lógica de una actitud de imposición del o los valores asociados a aquel "nosotros". Este "nosotros" queda definido, por tanto, como naturaleza/objetividad y representa el horizonte cultural a través del cual desplegamos sentidos de lo que se transforma en real y lo que no.

En este contexto, por tanto, la activación de un imaginario geográfico que dotase de unidad y forma a la espacialidad nación resultó, por tanto, vital (Ahumada, 2015). De este modo, el dominio y control territorial así como la fijación de íconos que otorgasen sentido de homogeneidad a sus habitantes fue del todo relevante. Como ha sido expuesto, las configuraciones de conocimiento y las formaciones discursivas de tipo geográfico se relacionan con sistemas de sujeción y control social y no pueden ser interpretados como ajenos, por ejemplo, a la homologación de montaña chilena con la idea de paisaje patrio (Navarro Floria, 2007; Núñez, 2017a).

La "naturalización" de Los andes chileno como límite llevó a que de modo reiterativo los discursos se encaminasen a resaltar su condición de enorme espacio geográfico: "Mole inmensa de nieve y granito [...] se alzará para siempre majestuosa y casi inabordable para los ejércitos que contrariando los designios de Dios y las indicaciones del destino manifiesto de los pueblos pretendan remontarla con fines de predominio y ambición" (Altamirano, 1899 en: Escolar, 2013). Con estas palabras el delegado chileno en la conferencia orientada a resolver el litigio de límites en torno a la Puna, celebrada en Buenos Aires en 1899, buscaba subrayar y cubrir a Los Andes de nieves eternas, lo que sumado a una gran altura interpretada como pareja y homogénea, permitiría delinear "geográficamente" de modo claro y rotundo a cada nación (Núñez, 2017a)

\footnotetext{
- Por mito comprendemos una estructura social permanente que involucra simultáneamente pasado, presente y futuro. Este significado es tomado de Lêvi Strauss quien lo ejemplifica en "La Historia" como el último mito del hombre. La Historia como se comprendió en el siglo XIX fue la instalación de un mito en la medida que en ella se proyectaba y consolidaba el sentido final de la humanidad olvidando un aspecto clave que solo la filosofía nietzscheana, heideggerriana y la hermenéutica filosófica expuesta por Gadamer se encargó posteriormente de exponer: que la memoria (y por ende la historia) ya está cargada de historicidad y que, por lo mismo, pertenece a un horizonte de comprensión. Como es sabido, la concepción de un tiempo lineal, de raíz cristiana, se reafirma con el racionalismo ilustrado y adquiere categoría de "mito social", como diría Levi Strauss, con Hegel y su "Historia Universal".
} 
Esa producción de un saber geográfico en torno a Los Andes como "línea" y "barrera" funciona hasta la actualidad como una homogeneidad isotrópica propia del espacio matemático clásico, es decir, euclidiano-cartesiano (Lefebvre, 2013: 142). Este horizonte de comprensión, sin embargo, invisibiliza y anula la existencia de una pluralidad de espacios sociales que subsisten como un palimpsesto y que están allí desplegándose como prácticas, como devenir de una cotidianidad. (Núñez, 2013). Como ha expresado De Certeau (2000), aquellas cotidianidades y prácticas parecen reapropiarse "del espacio organizado por los técnicos de la producción sociocultural", lo que lleva a observar reinvenciones y relecturas de lo que se comprende por "límite" o "barrera" cuando la escala de análisis es, precisamente, la cotidiana.

\section{Experiencia, lugar y el "arte de hacer"}

Como hemos venido expresando, la escala nacional, desde sus agencias estatales realizan una serie de esfuerzos orientados a "fronterizar" a los grupos sociales que las habitan, mediante la instauración, por ejemplo, de políticas excepcionales -del tipo "Zonas Especiales"- que focalizan y visibilizan los espacios de frontera de modo particular y distintivo con respecto al resto del territorio nacional"1. Entonces, interesa preguntarse, ¿qué lugar ocupan los espacios fronterizos en el conjunto del territorio nacional? o ¿qué tipo de re-significaciones adquieren estos imaginarios localmente? Para el caso que nos compete, la frontera local está mediada por la producción de aquel imaginario geográfico de escala nacional, pero, a la vez, por la singularidad de un tipo de presencia familiar -la familia Solís- que imprimió determinados rasgos que perduran hasta la actualidad, a pesar de la implementación de políticas destinadas a diferenciar el mundo nacional del internacional.

Los conceptos de "experiencia" y de "lugar", por tanto, adquieren un rol protagónico. Ambos, en efecto, están cruzados por el sentido del habitar y por el "arte de hacer" (Tuan, 1975, 2007; De Certeau, 2000; Bailly et al., 2017; Dardel, 2013). El lugar, desde esta perspectiva, es una construcción de la experiencia que se sostiene en lo material y en el conocimiento humano (Tuan, 1975). La experiencia transforma "la noción relativamente abstracta de espacio en una noción relativamente vivida y significativa de lugar" (Cresswell, 2008: 55), de esta manera encarna las experiencias y aspiraciones de la gente como una realidad que precisa ser clarificada y entendida desde las perspectivas de la gente que le dan significado (Tuan, 1975, 2007). El lugar, por tanto, es un centro de significados construido por la experiencia. La experiencia es un término que engloba la totalidad de maneras en que los humanos perciben y entienden la realidad a través de sus sentidos y mente: cómo conocen y cómo construyen lo que entienden por "realidad" (Tuan, 1975, 2007),

“...la realidad geográfica no es, ante todo un objeto; el espacio geográfico no es un espacio en blanco que se llene coloreándolo...la realidad geográfica, para el hombre, es, antes que nada, allí donde está, los lugares de su infancia, el entorno que lo atrae. La tierra que pisa o trabaja, el horizonte de su valle, o bien su calle, su barrio, sus desplazamientos cotidianos..." (Dardel, 2013: 94, el subrayado es nuestro).

De hecho, la legislación chilena (Ley No 1939 de 1977 por ejemplo) contempla una serie de restricciones orientadas a regular aquellas zonas sensibles donde se juega el sentido de "lo patrio". 
El quehacer cotidiano, desde este punto de vista, se desenvuelve en paralelo a los ejercicios del poder, a los entramados de las estructuras de vigilancia y de control de escala nacional, e incluso global. Es necesario preguntarse ¿qué trayectorias espacio-temporales, es necesario preguntarse, contienen el horizonte de comprensión de los habitantes de áreas llamadas marginales o fronterizas? Porque, en definitiva, el mundo ordinario del lugar, la rutina, el devenir del día a día se transforma en un misterio, en un silencio ausente frente a la homogeneidad que representa la escala nacional y el sentido de frontera como "línea" o "barrera":

"El territorio es espacio construido por y en el tiempo. De esta manera, cualquier espacio habitado por el hombre es producto del tiempo de la naturaleza, del tiempo de los humanos, de las distintas formas de organización, y de la concepción cosmogónica del tiempo. Es decir, en lo fundamental, el territorio viene a ser producto del conjunto de relaciones que a diario el hombre entretejió entre todos los suyos con la naturaleza y con los otros" (Ther, 2012).

Entonces, al afrontar el análisis de "lo fronterizo" ya no es posible, como ha sido la tónica recurrente en una literatura arraigada en una suerte de "nacionalismo metodológico", quedarse mirando el proceso definido como heroico con que se fue fabricando la "línea" y la "barrera".

Aquellas exploraciones, más allá de realizarse con el sólo objetivo de "descubrir" nuevos territorios, fueron reflejo y necesidad de una agencia estatal que colaboró a fijar el sentido/saber geográfico de los lugares en relación a una nación que se instalaba como "comunidad", y, por otra parte, fueron claves a la hora de invisibilizar prácticas, vivencias y experiencias del lugar que no se condescendían con el relato civilizatorio y de progreso con que, como expusimos al inicio, se iba narrando a la nación (Zúñiga y Núñez, 2017). De hecho, más que "des-cubrir", dichas exploraciones "cubrieron" la comprensión de la zona con una renovado horizonte hermenéutico. Un claro ejemplo de lo que exponemos fue el "silencio geográfico" con que se fue dibujando y memorizando aquel ámbito lo que se iba conociendo por "Patagonia-Aysén" y al que nos referiremos en el siguiente apartado.

Un último aspecto es esencial/relevante para el análisis de lo que hemos denominado "las fronteras cotidianas": no se debe caer en lo que el propio Bhabha denomina un "exceso de identidad" (2013: 72). En efecto, las prácticas y las cotidianidades, lejos de asumirse con neutralidad, constituyen uno de los elementos clave desde donde debe afrontarse el análisis fronterizo. Sin embargo, el texto social de la práctica local pone en relieve el juego intercultural desde donde se produce y desenvuelve la relación entre lo nacional y lo local o entre lo local y lo global, en lo que la geógrafa inglesa Doreen Massey ha denominado el sentido "global del lugar" (2012): "La identidad de un lugar -cualquier lugar- no está arraigada únicamente dentro del lugar, sino que está compuesta también por relaciones externas". Esto es relevante por dos aspectos que no deben perderse de vista. Por una parte, permite alejarse de aquello que Grimson (2011) ha denominado críticamente la "cultura de la identidad", es decir, un romanticismo e idealismo de lo que constituye el lugar como espacio de autenticidad esencial. Por otra parte, también evita caer en discursos de tipo posmodernos que buscan ver en la "diferencia" o en la "otredad" una multiplicidad de posibilidades de expresión social y cultural, donde los juegos de poder quedan excluidos ante tal multi-culturalismo.

Así, en definitiva, nos interesa constatar que junto al despliege y producción de una narrativa fronteriza de tipo nacional, existen expresiones multiescalares que desde su experiencia, de su sen- 
tido del habitar pueden entrar en una suerte de negociación de los significados, a veces en tensión y otra no, de lo que es realmente un espacio fronterizo (Benwell, 2016). El texto de la colonialidad de la construcción de la nación (cuya matriz interpretativa supone que Los Andes o la frontera es una "línea" o una "barrera"), como expone el propio Bahbha (2013), no puede desencadenar en un relativismo radical, donde la "otredad" o "diferencia" funcionen como una institución social más entre muchas otras. Lo que debería estar en juego, desde nuestro punto de vista, es precisamente que aquellas "fronteras cotidianas" poseen un mundo y que desde aquella posición pueden reconstituir y reinventar desde sus historias otras posibilidades a la historia dominante de tipo lineal y teleológica. Así, el discurso de la frontera lineal no es sino un apartado o apéndice del discurso de la modernidad, en la medida que es la excusa para limitar y controlar los espacios de las fronteras cotidianas.

\section{Los Andes como lugar: Lago Verde-Las Pampas y la memoria de una frontera}

La literatura específica data la ocupación moderna del área de Lago Verde-Las Pampas ha sido en general fijada a principios del siglo XX. Antes y en paralelo, como ha sido expuesto a partir de los estudios de Osorio (2013) Núñez et al. (2016) y Saavedra (2002, 2016), hubo un constante nomadismo indígena que fue invisibilizado por un tipo de comprensión que organizó el saber geográfico únicamente en relación a lo fijo y en lo estable. Ello repercutió en validar la propiedad privada como eje estructural del poblamiento austral y en invalidar la movilidad o nomadismo como racionalidad del habitar,

“...Patagonia-Aysén, tanto en los siglos XVIII y XIX como en el XX, incluso en la actualidad, ha sido el resorte de un imaginario geográfico de escala nacional, es decir, una reproducción social y territorial acorde a esa lectura. Aquello llevó a invisibilizar una comprensión del espacio desde una perspectiva nómade y, por lo mismo, a silenciar y vaciar esas ocupaciones y a resaltar una espacialidad estática asociada a las concesiones ganaderas iniciadas en el siglo XX... Desde esta perspectiva, Patagonia-Aysén deviene desde el siglo XIX, como el área argentina, en "desierto". De algún modo la movilidad indígena-chilota fue ocultada y la articulación a Chiloé de estos territorios insulares sufrió igual camuflaje, de modo de erigir un espacio vacío, acorde a las políticas y el discurso de la colonización del siglo XX, que desmereció la presencia y la agencia local, valorizando y resaltando únicamente el sentido del espacio proyectado desde un texto centro-periferia" (Núñez et al., 2016)².

En la práctica, los primeros habitantes siguieron el derrotero de otros muchos pobladores que provenientes de la Araucanía pasaron a Argentina y que deambularon en busca de tierras hacia el sur del lago Nahuel Huapi (Bariloche) ${ }^{13}$. Así, aunque estos habitantes fueran de nacionalidad

\footnotetext{
Incluso el proceso de colonización que marcó gran parte del siglo XX sirvió para resaltar el sentido "patriótico" (en tanto proceso "heroico"), aun cuando poco se sabe de sus historias locales. La historia de Aysén, como la de Chile, ha estado marcada por el patrón hermenéutico de "Io nacional". Solo en las últimas dos décadas han aparecido trabajos que reinterpretan esa memoria. A los ya mencionados de Osorio (2013) y Saavedra $(2002,2013)$ agregamos el texto de Patricia Carrasco (2017).

13 Al respecto hay dos asuntos a destacar. Primero que los territorios de Araucanía- Norpatagonia Argentina durante el siglo XIX y gran parte del XX fueron comprendidos como un conjunto de relaciones territoriales. De hecho, como ha expuesto Bello (2011), el Este "argentino" era, en la práctica, el "norte". Es decir, su concepción del territorio era horizontal y no vertical. Segundo, que la Campaña del Desierto impulsada por el General Roca en Argentina generó presión a estos habitantes "chilenos" (la mayoría instalado en el área de Neuquén) e hizo movilizarlos en busca de nuevas tierras para vivir.
} 
chilena, su horizonte cultural estaba imbuido por prácticas históricas de tipo gauchescas por su larga permanencia del lado Este de la cordillera de Los Andes. En este contexto, los primeros pobladores arribaron a la zona hacia la década de 1910. Eran tierras sin cercos ni mediciones de ningún tipo. Los tiempos de viaje eran de varios días y se hacían en carretas tiradas por bueyes (Martinic, 2014). Las referencias geográficas no eran "Lago Verde" ni "Las Pampas", eran más bien campos para que los animales "veranearan e invernaran" según sus necesidades y terrenos donde desplegar sus sueños.

Como era costumbre de estos primeros habitantes, su hábitat siguió constituyéndose a partir de siendo una comunicación permanente con asentamientos argentinos como Río Pico u otros, ubicados varios kilómetros más hacia el interior de los llamados Territorios Nacionales Argentinos de la Patagonia. Como expresa un habitante actual de Lago Verde, cuya familia también se instaló hacia inicios del siglo XX en la zona, "aquí no había nadie...y los campos simplemente se ocupaban, aunque eran los Solís los que entraron primero" (Oyarzo, nieto de Carlos Oyarzo, de los primeros pobladores). Por largos años, aquellos habitantes por largos años comprendieron su territorio en relación a Argentina, en la medida que conseguían allí sus víveres y realizaban los intercambios permanentes de diversa índole. Solo hacia 1936 se destinaron algunos terrenos para proyectar una población más estable. También hacia 1945 se creó una pista aérea que iniciaría la construcción o maduración de un imaginario geográfico de tipo nacional (Martinic, 2014),

“(En Lago Verde).. la colonización fue iniciada por Antonio Solís Martínez, quien ingresó a ese lugar en el año 1914. Junto con Antonio Solís o un poco más tarde lo hicieron Claudio Solís, Francisco Vásquez, Carlos Soldán, Germán Jaramillo, Germán Willer. En 1921 lo hace el argentino (hijo de chilenos) Carlos Oyarzo. Lago Verde fue por años un centro rural de completa dependencia argentina en materia de abastecimiento de alimentos hasta 1945, fecha en que se habilita una pista aérea..." (Araya, 1998).

Así, las prácticas y el sentido del habitar estuvo marcado por el ritmo marcado del manejo de los animales y de los intercambios y relaciones "fronterizas". La familia Solís fue la predominante y ocupó los valles de lo que posteriormente se reconocerían como Lago Verde y Las Pampas.

En paralelo, la narrativa nacional, a través del Estado centralizado, otorgaba hacia inicios del siglo XX concesiones a empresas ganaderas transnacionales, predominantemente de capital inglés, para que desarrollasen la zona desde una perspectiva estanciera y ganadera, imitando las lógicas precedentes llevada adelante en Magallanes y en la Patagonia argentina ${ }^{14}$. Nos resulta muy relevante constatar cómo el despliegue de los dos lenguajes fue otorgando significados al espacio y respecto de quiénes tenían reales derechos ${ }^{15}$. En efecto, hacia 1918 en lo que se ha denominado "La Guerra de Chile Chico", mucho más al sur de Lago Verde, pero como parte del mismo proceso, se produjo una tensión entre los estancieros y los pobladores. Por una parte, los

14 Como consecuencia de la proyección de la ocupación de Magallanes en la región de Aysén se instaló un orden rural particular y "único en Chile" que predominó sin grandes cambios hasta el tercio final del siglo XX: "Como consecuencia de la implantación y vigencia del sistema de trabajo rural-ovejero de origen británico, fue connatural al mismo que la modalidad de vida que hubo de imperar en los campos ganaderos -donde los empleados de ese origen (escoceses principalmente, ingleses, galeses, irlandeses, malvineros, neozelandeses y australianos y sus descendientes chilenos o argentinos) fueron desde un principio mayoría- adquiriera o reflejara un forma ajustada cabalmente a los cánones de la tradición británica en lo referido a uso de idioma, hábitos corrientes, formas culinarias, gustos culturales, etc." (Martinic, 2014, 256)

15 Respecto de la Sociedad Industrial de Aysén, una de las empresas capitalistas más exitosas instaladas en la zona, el ingeniero José Pomar escribía en 1923 que "regresar del Valle Simpson a la concesión del Aisén es pasar de un ambiente argentino a otro británico" (Pomar, 1923: 108). 
estancieros, representantes de las políticas públicas del Estado central sustentaban su ocupación en documentos otorgados desde Santiago (Chile) y los otros, los lugareños, se legitimaban en base a su habitar permanente. Sin duda, aquellos pobladores o lugareños colonos concentraban en ese proceso una buena dosis de ausencia y lejanía respecto de la instancia de poder de quienes definían la "chilenidad" y la "comunidad imaginada" de la nación”.

En el caso de Lago Verde - Las Pampas, los íconos de aquella "chilenidad" estaban dados por contraste. En efecto, a pesar de la ocupación espontánea de tierras en una vasta territorialidad asociada a la Patagonia, en 1918 con la consolidación de los Territorios Nacionales en Argentina, se fundó en el sector de Las Pampas la primera escuela de la zona y ello hizo que el reflejo de las naciones se hiciese más presente y consciente ${ }^{17}$. La línea fronteriza, sin embargo, continuó difusa por largos años. Como expresa una nieta de Antonio Solís. "Mis abuelos miraban el límite y en realidad miraban campos". Una vez medido o definido el límite, a través de las respectivas Comisiones, junto a un mayor orden de los campos y sus ocupantes, la familia Solís y otros habitantes del sector, tuvieron que "definir si eran argentinos o chilenos". Sin embargo, más allá de aquella imperiosa definición, los lazos familiares y de amistad continuaron a lo largo del tiempo, generando un modo de ser fronterizo-fronteriza en estos grupos emparentados no sólo de modo consanguíneo, sino por interrelaciones cotidianas profundas en el espacio "lagoverdino-pampeño". De hecho, hasta el día de hoy el límite divisorio está representado por un portón que junto a su legalidad convive con su propia levedad y con el simbolismo de un "ir y venir" (Figura N 1).

Figura $\mathrm{N}^{\circ} 1$

Límite divisorio "lagoverdino-pampeño"

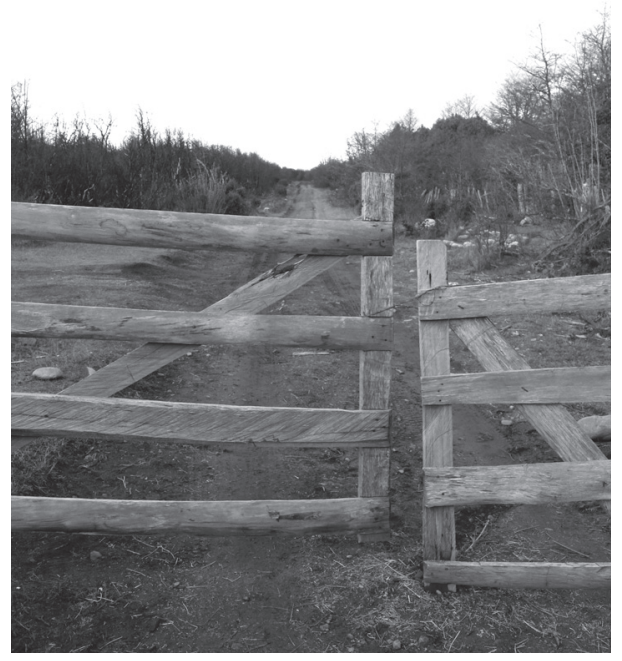

Fuente: Archivo fotográfico de los autores (mayo, 2014)

Los trabajos de la historiadora local Danka Ivanoff $(2011,2014)$, permite para visualizar no solo el modo de vida de los primeros habitantes sino sus silencios, sus huidas y sus prácticas.

17 Nos referimos a la escuela como artefacto estatal disciplinario en el sentido dado por Foucault. 


\section{"Los Solís" en la frontera Lago Verde-Las Pampas. Simetrías y asimetrías fronterizas}

Las localidades que componen el Paso Fronterizo Lago Verde-Las Pampas, se encuentran a 10 kilómetros de distancia (Figura $N^{\circ}$ 2). En el caso de "Las Pampas" posee de acuerdo a los datos del Censo Nacional de 2010: 44 habitantes, de los cuales 28 son varones y 16 son mujeres. La población es administrada a través de una institución denominada Comuna Rural, y conducida con el cargo de Presidente de Comuna (Dirección General de Estadística y Censos). En el caso de Lago Verde de acuerdo a los datos del censo 2012, cuenta con 869 habitantes, los cuales no solo residen no sólo en el casco urbano, sino también en la zona rural ${ }^{18}$.

Figura $\mathrm{N}^{\circ} 2$

Localización de los poblados de Lago Verde (Chile) y Las Pampas (Argentina)
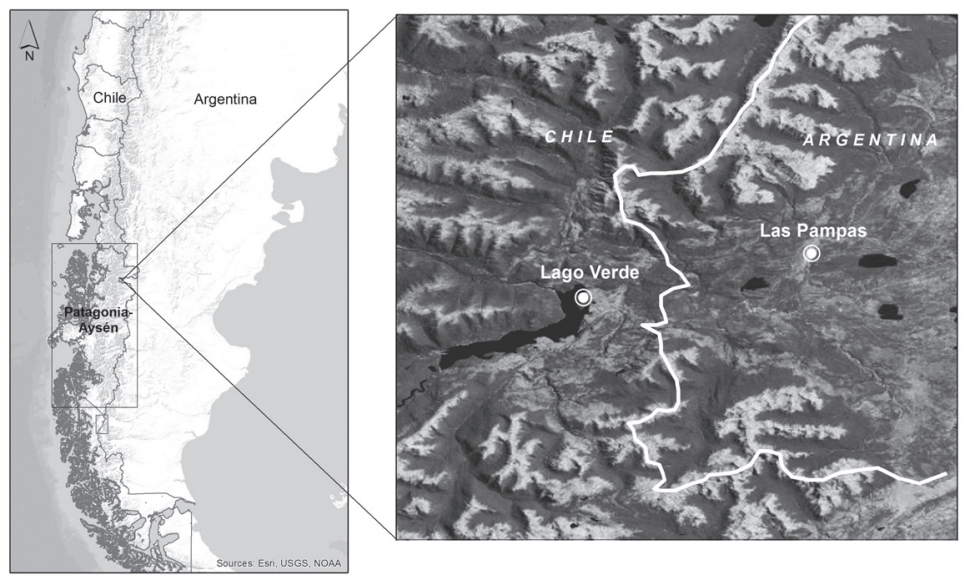

Fuente: Elaboración propia.

Aunque Los Andes chileno-argentinos presenta una porosidad notoria a lo largo de toda su extensión, donde las prácticas, los cruces y las relaciones son parte del engranaje fronterizo (Núñez et al, 2013), el Paso Fronterizo Lago Verde-Las Pampas adquiere una dimensión especial tanto por la posición clánica presente allí como por la evidente cercanía entre un poblado y otro. Por lo mismo, se construye y constituye como lugar donde la sociabilidad con el "otro fronterizo" es cotidiana (Benedetti y Laguado, 2013). Hasta 1970 aproximadamente, según se nos narró en el trabajo de campo, el cruce se hacía a diario y a través de huellas para caballos. Ese año, la huella fue ampliada y permitió el uso limitado y esporádico de vehículos motorizados. Los tres ríos que existen entre Las Pampas y Lago Verde si bien impactan en la fluidez de los cruces e intercambios, representan, junto a su materialidad, una "experiencia geográfica" (Dardel, 2013: 97) en la medida que ellos son parte del paisaje de una memoria que los ha llevado a convivir con esos cursos de agua por largas décadas. En efecto, la localización y presencia de esos ríos se posiciona en ese "paisaje de la experiencia social" del área y adquiere sentido solo para sus habitantes o para los que necesitan dialogar con esos ríos. Así, los ríos son relaciones recíprocas entre lugares y una

http://www.lagoverdeaysen.cl/web/index.php/2013-12-05-03-10-53/historia-de-lago-verde 
temporalidad del habitar que es también historicidad de ese lugar. De este modo, por ejemplo, en invierno "los ríos tienen su impacto", pero, como fue enfatizado, "igual los cruzamos".

En la práctica, fue la declaración oficial del Servicio Agrícola Ganadero (SAG-Chile) de prohibir el cruce de caballos al lado argentino por el peligro de la fiebre aftosa (2001) ${ }^{19}$, afectó las prácticas de veranadas y supuso el levantamiento de la frontera. Los relatos de los habitantes locales rememoran con nostalgia las épocas en que se cruzaba la frontera a caballo. Sin embargo, como nos narró la nieta de Claudio Solís, "el uso de la camioneta hizo las cosas más fáciles". Ella refiere a que el caballo era una costumbre arraigada ("viajábamos por el día"). "El caballo marcó la pauta ya que acá nos abastecíamos de Argentina y uno traía sus cosas... el caballo era rápido, 4 horas ida a Las Pampas... ahora con los vehículos se ha hecho aún más expedito, a pesar de lo malo del camino...". En la actualidad a pesar del alzamiento de la prohibición de cruzar con caballos, los habitantes lo siguen haciendo mayoritariamente en camioneta ${ }^{20}$.

De acuerdo a Benedetti y Laguado (2013: 474), en el año 2009 se produjeron 231 cruces oficiales, 253 en el año 2010 y 378 en el año 2011. Sin embargo, en la comprensión social del espacio fronterizo muchos cruzaban -hasta el día de hoy- de modo no oficial, "porque ya nos conocen e íbamos por el día" o "porque cruzábamos por los numerosos pasos o huellas que existen en la zona".

Entonces, el hecho de no constituir una frontera de cruce diario, en una suerte de ir y venir constante, nos obliga a reflexionar acerca de qué tipo de frontera se trata. La nieta de Claudio Solís, por ejemplo, habló de "frontera familiar". Sin embargo, consideramos válido pensar la idea de frontera desde el concepto de territorio. Nos parece que si se "territorializa" la frontera el asunto adquiere otras dimensiones. Como se expuso en las páginas iniciales, si relacionamos territorio y memoria, espacio y experiencia geográfica, "la realidad geográfica" es, antes que nada, el recuerdo y las prácticas que vinculan al hombre con la tierra, con el habitar: "La realidad geográfica, para el hombre, es, en primer lugar, allí donde está, los lugares de su infancia, el entorno que le atrae. La tierra que pisa o trabaja, el horizonte de su valle, o bien su calle, su barrio, sus desplazamientos cotidianos..." (Dardel, 2013: 94). Desde esta perspectiva, la relación parental (familiar) y la memoria de campos ganaderos que se abrían -y abren- en un horizonte relacional nos lleva a calificar de "frontera cotidiana" al paso Las Pampas-Lago Verde (Figura №3).

En este sentido, de modo similar a las comunidades indígenas, aquí no existe separación entre lo natural y lo social, sino que se imbrican en un todo complejo. Es decir, la "delimitación territorial de la dimensión social, se vincula al poblamiento, organización de la comunidad, lazos de parentesco y relaciones familiares dentro de un espacio que puede abarcar una o más de una comunidad [...] Es decir, lo social puede rebasar los deslindes de la propiedad poseída individualmente o de manera comunitaria..." (Molina, 1995: 116).

19 La fiebre aftosa es una enfermedad viral que afecta a todos los bovinos, caprinos, porcinos, ovinos, rumiantes salvajes y camélidos. Es altamente contagiosa entre animales, produce fiebre, baja del consumo de alimentos, disminución en la producción de leche y finalmente la muerte.

20 En el año 2014, la Patagonia argentina fue declarada zona libre de aftosa, ver nota: "Declaran a toda la Patagonia argentina como Libre de Aftosa Sin Vacunación", Secretaría Comunicación Pública. Presidencia de la Nación. Disponible en Internet: http://prensa.argentina. ar/2014/05/29/50318-declaran-a-toda-la-patagonia-argentina-como-libre-de-aftosa-sin-vacunacion.php 
Figura $\mathrm{N}^{\circ} 3$

El paso Las Pampas-Lago Verde como "frontera cotidiana"

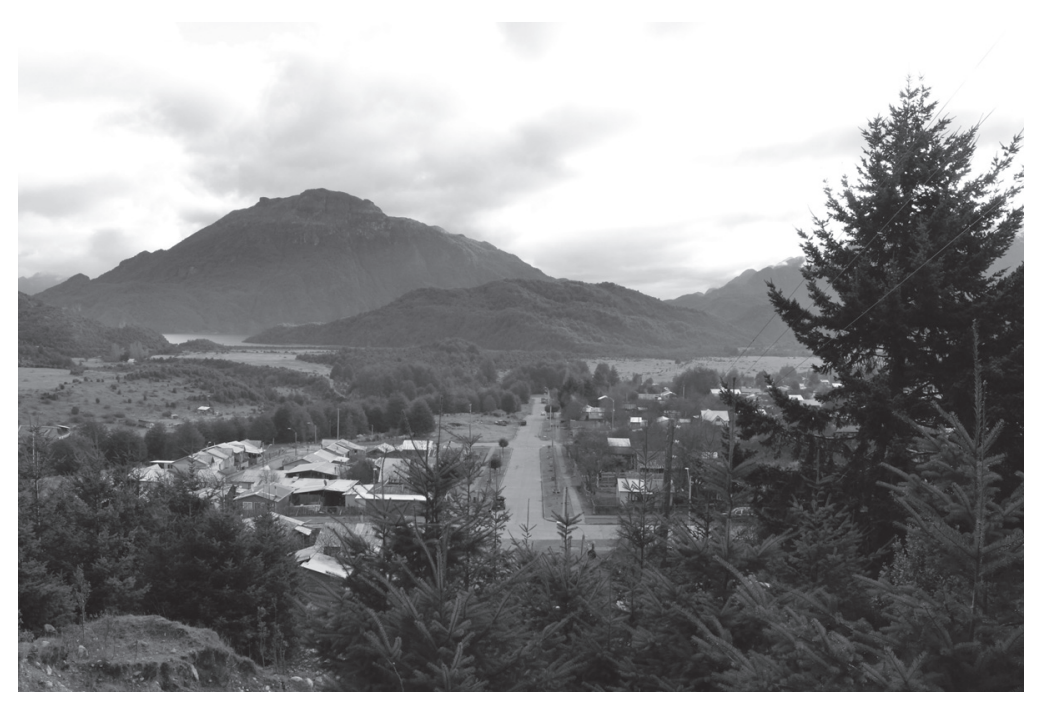

Fuente: Archivo fotográfico de los autores (mayo, 2014)

¿Qué significó para la familia Solís -y tantos otros- el trazado de los límites estatales fronterizos hacia 1936? Por una parte, implicó que el horizonte de las naciones chilena y argentina se materializó con la instalación de un hito, que fue el símbolo de su presencia (Figura $\left.N^{\circ} 4\right)$. Sin embargo, la vida continúo en diálogo con Las Pampas, porque allí estaban "los parientes... los de allá y nosotros". Así, "pasar al otro lado" no significó separación, dado que el modo de resolver las necesidades de alimentación, vestimenta y otras demandas, tales como la atención sanitaria, fueron canalizadas a través del contacto con el lado argentino de la frontera. Antes de la década de 1970 se tardaba un mes para ir a comprar víveres a Río Pico (Chubut, Argentina), trayecto que se realizaba con 'pilcheros ${ }^{21}$ y carros $^{22}$ (Néstor Opazo, Alcalde de Lago Verde). De hecho, como expresamos anteriormente, el Estado Nacional Argentino ya había instalado una escuela en Las Pampas (1918), artefacto que, sin duda, actúo como uno de los primeros íconos de referencia a lo nacional.

En este contexto, los lazos culturales históricos y de parentesco entre los propietarios y los peones rurales, chilenos o argentinos, donde la gran mayoría son parientes, son los que mantuvieron -y mantienen- la continuidad de prácticas que remiten tanto a la nación como al espacio cotidiano desde donde se despliega el habitar (ya sea al ritmo de las estaciones o al de las necesidades de los animales). En la actualidad, fue posible observar, una mayor conexión con el pueblo de La Junta en la parte central de la región de Aysén (Chile), básicamente porque se mejoraron las comunicaciones terrestres entre lago Verde y ese pueblo. A su vez, el desarrollo de las actividades

Caballos usados por los arrieros para cargar mantas, comidas, utensilios, entre otros elementos indispensables para el viaje.

2 Entrevista al Alcalde Néstor Opaso. Lago Verde, Chile, 23 de mayo de 2014. 
Figura $\mathrm{N}^{\circ} 4$

Hito, símbolo del límite estatal entre Chile y Argentina

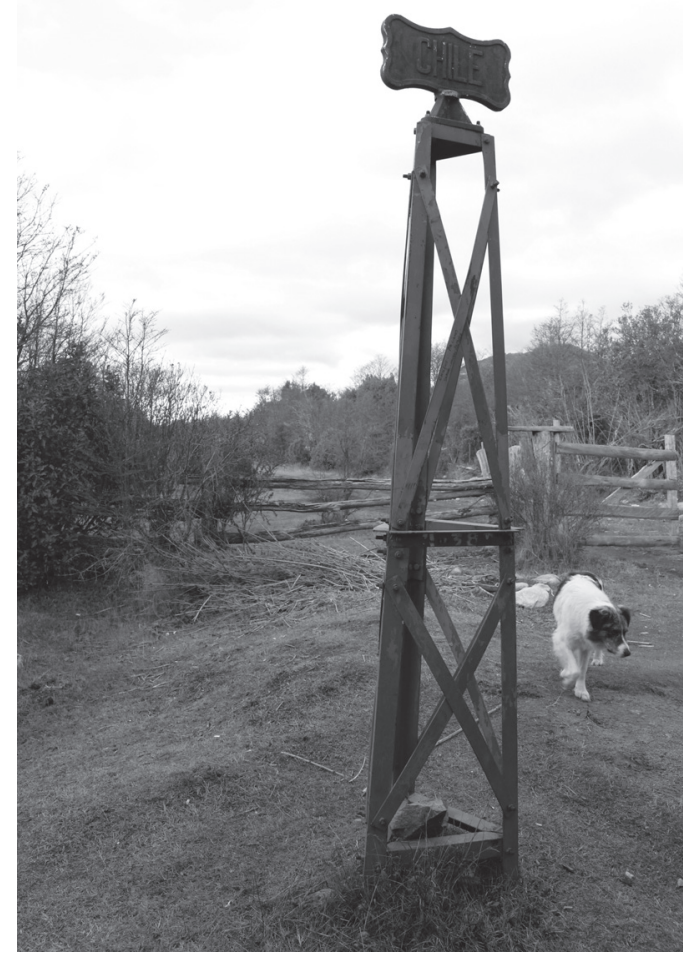

Fuente: Archivo fotográfico de los autores (mayo, 2014)

turísticas (todavía incipiente), ha llevado a que el habitar de las familias locales también incorpore nuevas experiencias en clave global.

Tal vez precisamente por esta renovada relación de lo local ahora con lo global, se recuerde con tanta nostalgia las épocas en que las relaciones fronterizas eran del todo fluidas, que implicaban un ir y venir constante, y que suponían lazos que se comenzaban a construir desde la infancia. A pesar de que hoy existe mayor intensidad de cruce en verano que en otras épocas del año, básicamente, porque es cuando se realizan las festividades que refieren a fechas que celebran la presencia de los pobladores a ambos lados de la frontera, la imagen de un paisaje familiar sigue latente ${ }^{23}$. Esto además se hace presente a través de la constante recuperación de una memoria territorial arraigada en los lazos familiares. Una de las entrevistadas en el lado chileno de la frontera, y que forma parte del "clan Solís", integra un grupo que trabaja en recuperar la historia de la frontera Lago Verde-Las Pampas. Ella nos explicó que Claudio Solís Vega pasó a Lago Verde y que junto con otras familias como Oyarzo o Figueroa se fueron emparentando entre ellos. En un estu-

23 Por ejemplo, los encuentros costumbristas en Lago Verde y la "Fiesta de la Cordillera" en Las Pampas. 
dio denominado "Historias de memorias vivas" se registraron más de 150 integrantes en el árbol genealógico de "los Solís", sólo del lado chileno, aunque ellos reconocen que faltaron "las patitas argentinas", tal como una de las entrevistadas manifestó. Esta familia "clánica" de tipo patrilineal es considerada como "pionera" no sólo por "llegar primero", sino por el proceso de colonización que llevó adelante a partir de la subdivisión de las propiedades para cada heredero de familias que llegaban a tener entre 11 y 17 hijos cada una. Así el reparto de tierras no lo hizo el Estado, sino la familia con sus ocupaciones- Una de las nietas recuerda: "El abuelo tenía un sistema de vivir: cuando se casaba un hijo, él le entrega tierra, ganado, casa" (Hilda Soto). Sin duda, resulta interesante constatar que eran estos vecinos chileno-argentinos los que "repartían" las tierras. Con la instalación de la "línea fronteriza" (1936) los parientes, como dijimos, tuvieron que optar por una nacionalidad. Así, un grupo de hermanos quedó del lado chileno y otro grupo del lado argentino (Figura $\mathrm{N}^{\circ}$ 5). La imposición de la cartografía estatal-nacional sobre las familias Solís, y otras como aquellas constituidas por los Oyarzo o los Jaramillo, entre otros grupos, provocó, en cierto modo, una ruptura con el modo previo de organizar el espacio, donde en los primeros tiempos "no había límites, sólo estaban los límites familiares" (Cristina Solís, Jefa Comunal de "Aldea Las Pampas-Atilio Viglione). Sin embargo, desde la comprensión del caso de "los Solís", los vínculos han seguido tejiéndose hasta la actualidad. En realidad, en la práctica impera la idea de "clan territorial" (Sahlins, 1972). Este trasciende los límites fronterizos nacionales, ya que de ambos lados los y las Solís, emparentados, se empeñan por reconstruir la genealogía y mantener vivo "el valor humano de los espacios de posesión..., de los espacios amados" (Bachelard, 2010: 28) ${ }^{24}$, es decir el lazo afectivo construido con estos ámbitos (Tuan, 2007).

La de "Lago Verde-Las Pampas" es un tipo de frontera que es posible traspasar de modo casi imperceptible, en la cual por juntar murillas (hongos) y casi sin darse cuenta un poblador-a de Lago Verde puede "aparecer" en el lado argentino de la frontera. O bien, un grupo de "pampeños" arreando vacas puede "aparecer" en Chile. Televisores o celulares que provienen de Chile, son "esperados" por familias argentinas en algún lugar inhóspito de la frontera, prestos al intercambio. Puesteros que pasan de un lado al otro de la frontera "sin avisar", porque es chileno y trabaja en un campo del lado argentino, o viceversa. Así, a pesar -y junto a ella- de la colonización estatal tanto de Chile y Argentina, sobreviven aquellas prácticas relacionales que remiten a la unión de las familias "clánicas" que fueron divididas a partir de hitos, mojones y marcas de fronteras estatales. Una de las entrevistadas en Lago Verde, recuerda: "Cuando fallece alguien conocido, nos quedamos allá (en Las Pampas), acá son largos los velorios, duran 72 horas, siempre se carnean animales, nos alojamos en la casa de algún pariente, nos vamos donde unos primos y ellos por años vienen a nuestra casa..." (Hilda Soto). También sobrevive la práctica de "intercambio de regalos", por ejemplo en el caso de algunas bebidas, como pisco por coñac, vino por sidra, o de algunos alimentos, como pan por manteca, entre otros "dones y contradones" que los continúan entrelazando a unos con otros. Estas prácticas, desde nuestro análisis, remiten a la persistencia de un tipo de comunidad donde más allá de la consanguineidad, la vecindad y otros modos de parentescos remiten a un modo de relacionarse muy distante a la que se observa en la mayor parte del mundo urbano-moderno occidental.

\footnotetext{
24 El concepto de Topofilia es muy útil para explicar la proceso de vínculo de "Los Solís" con el valor de una tierra que puede ser homologada a un espacio vivido, que trasciende desde la cotidianidad la organización fronteriza de los tecnócratas ubicados en un centro en muchos casos lejano y ajeno. Topofilia nos remite al amor por el lugar, al arraigo que significan los lugares y al vínculo emocional que poseen los habitantes la tierra del habitar (Tuan, 2007)
} 
Figura $\mathrm{N}^{\circ} 5$

Un "Solís" en la "frontera"

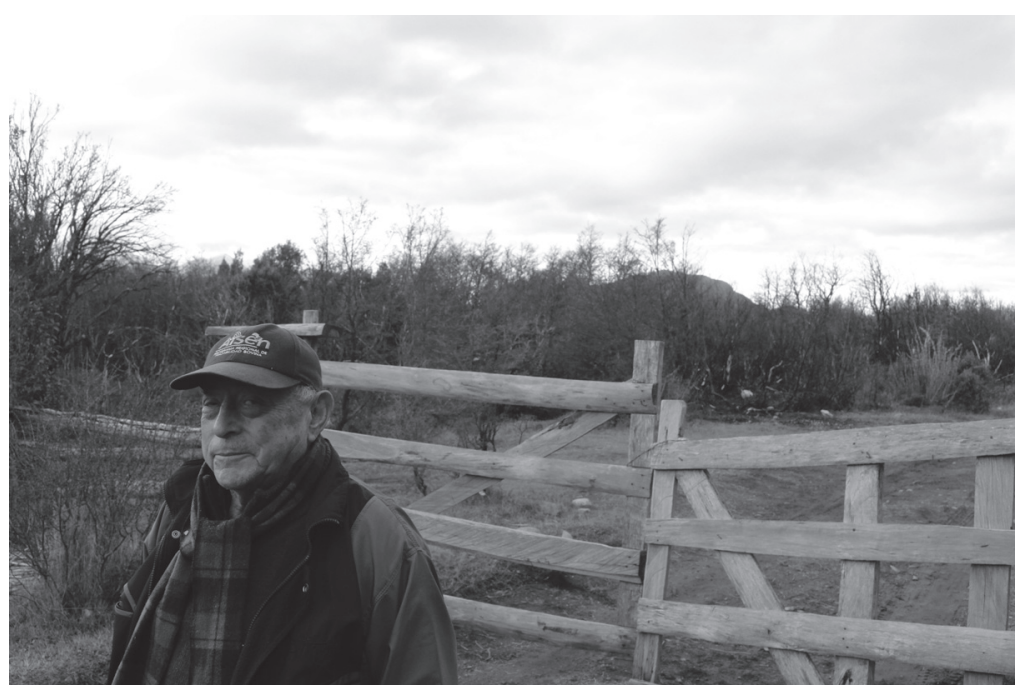

Fuente: Archivo fotográfico de los autores (mayo, 2014)

Sorprendente es el relato que hacen los pampeños "argentinos" al referirse a la celebración patria chilena del 18 de Septiembre. Como nos expusieron con entusiasmo, muchos de "los Solís" (que como en Lago Verde también son muy numerosos en Las Pampas) esperan "con ansias" la fecha, "porque en Argentina el 25 de mayo se celebra un día, en cambio en Lago Verde las fiestas duran 1 semana... entonces, nos vamos todos para allá con nuestros parientes y celebramos la semana entera...este pueblo [Las Pampas] queda vacío" (joven Solís del pueblo de Las Pampas). De esta manera, nos parece relevante destacar de qué modo la colonización estatal generó determinadas prácticas que han sido re-significadas en celebraciones, festividades y que otorgan ¿nuevos? sentidos a la vida fronteriza. Pero que, de modo paralelo, se imbrican con otras cotidianeidades donde la agencia de los Estados nacionales parece "aceptar" como parte del proceso de "fronterización".

El paso fronterizo Lago Verde-Las Pampas constituye así un in between para ambas agencias estatales a las que pertenecen. Con poblaciones emparentadas entre sí, con lazos comunes desde la conformación de ambas comunidades, con perspectivas y dinámicas similares desde la experiencia del territorio, con redes sociales que desdibujan los bordes estatales, el área deriva en prácticas y saberes de lo que hemos denominado una "frontera territorial/relacional/cotidiana", que viene a poner en perspectiva y a problematizar la dimensión de poder del límite/línea/barrera de la nación.

De acuerdo a la información y los relatos de uno y otro lado de la frontera, la experiencia de "soledad" o "aislamiento" se vive de modo diferente. En el caso de Lago Verde sobrevive el deseo de estar conectados con el lado argentino, entonces se esperan las obras que construirán puentes y caminos para agilizar el contacto. En una de las entrevistas nos relataron: "...nuestro sueño sería que Argentina se interese por nosotros... Nosotros (en ellos) nos miramos a nosotros 
mismos... estamos más cerca de Argentina... hoy miramos para la Junta no más... el camino nos corta la visión" (Gladys Opaso) Sin embargo, aquella espacialidad es dinámica y móvil y, en paralelo, se re-significa desde la comprensión de una "chilenidad"|"argentinidad" que los moviliza en una textualidad identitaria de tipo nacional, donde, por ejemplo, las banderas, las escuelas, las celebraciones patrias, fabrican un camino de racionalidad histórica que los lleva a imaginar que también pertenecen a una "familia" más amplia, a una "comunidad" que los organiza socialmente y de la cual no pueden evadirse. Como todo, la frontera de Lago Verde-Las Pampas concebida como "experiencia territorial", como memoria que sustenta el caminar, el hacer diario y el saber (se) familiar, hace que muchas veces, tal vez la mayoría de las veces "la nación les quede lejos".

\section{Conclusión}

Las distancias físicas son antes que nada discursivas (Dardel, 2013; Aliste y Núñez, 2015). Para el caso, de la frontera Lago Verde-Las Palmas es el relato de una significación cultural de tipo nacional que marca y define una territorialidad que, en la práctica, también se desenvuelve bajo otros ritmos y valores. Bajo otros olores, otros recuerdos y otros colores. ¿Qué vínculo tiene el tiempo medido "a caballo" con una temporalidad instalada en Santiago o Buenos Aires? Desde Las Pampas nos recuerdan que "mi abuelo decía... lo que sucedió es que éramos toda una familia, un espacio y cuando pasaron los límites nos dividieron..." (Cristina Solís).

La idea de pertenencia familiar, de esta "frontera familiar" como la llamaron, adquiere un tipo de valoración extrema, porque se genera una noción de arraigo con el territorio, de "topofilia", a partir de aquel lazo familiar. Por eso, es difícil poder obtener reconocimiento para aquellos que no pertenecen al "clan Solís" o a las familias de los primeros ocupantes, en estos casos es necesario poseer algún tipo de capital económico o simbólico que permita "ser reconocido". Aquello es aún más marcado cuando desde la localidad aledaña de Río Pico (ubicada a 30 kilómetros de distancia de la de Las Pampas) se concibe a la población de "Las Pampas" como una unidad socio-territorial emparentada con Chile, y en particular con un grupo étnico, como es el de "los chilotes". De hecho, los habitantes de Las Pampas son reconocidos o identificados como "chilotes" para refrendar su vínculo emocional con Lago Verde.

Como fue expuesto, estimamos que el caso de estudio es un claro ejemplo para reflexionar en torno de los aportes que brinda el debate en torno a la des-colonización de los procesos de "fronterización" de dos localidades aledañas a un paso fronterizo donde las políticas de colonización estatal argentino-chilena instalaron artefactos sociales que re-significaron, aunque parcialmente, las vivencias/experiencias de una familia "clánica". Si bien sabemos que se podría tratar de una extrapolación de categorías, pensar la familia extensa de "los Solís" desde el concepto de clan nos permite agrupar no sólo a los integrantes que residen en el mismo lugar, sino a aquellos que por los vínculos de arraigo en ambas localidades fronterizas, se siguen considerando parte del clan, por portar el apellido o bien por algún tipo de lazo sanguíneo que genera filiación al mismo.

En nuestro caso de análisis, la frontera chileno-argentina dejó a "los Solís" de uno y otro lado, pero no logró destruir los vínculos de relaciones entre sus miembros, al punto que de modo cotidiano (de acuerdo a cómo hemos comprendido acá el término) en numerosos momentos de sus vidas, de su pasar, continúan profundizando sus lazos a través de reuniones y encuentros familiares. Tal como señala Sahlins: 
"No todos los próximos parientes de un individuo viven en las cercanías. Y los miembros de un clan, aun cuando habiten a gran distancia río abajo y no se haya trabado antes conocimiento con ellos, deben ser tratados con consideración: son hermanos, no extranjeros... Y como la calidad del parentesco se relaja con la distancia social, la de la consideración es estimulada" (Sahlins, 1972: 35-36).

Por lo mismo, pensar la frontera tratando de "descolonizarla" representa la búsqueda de estos esquemas de pensamiento que efectivamente desentronizan el proceso de colonialidad (Spedding Pallet, 2011: 90) organizado desde los Estados centrales (o por un capital globalizado) y reproducidos también por narrativas sociales que de modo muy pedagógico se encargan de construir comunidades o imágenes culturales/identitarias que, muchas veces, poco o nada tienen que ver con los sueños cotidianos y con el habitar de localidades que parecen vivir otra narración, otro proceso de significación sociocultural y, por lo mismo, a veces, especialmente en el arte de hacer, "la nación les queda lejos".

\section{Referencias bibliográficas}

AHUMADA, P. Paisaje y nación: la majestuosa montaña en el imaginario del siglo XIX. En: PELIOWSKI, A. y VALDÉS, C. Una geografía imaginada. Diez ensayos sobre arte y naturaleza. Santiago de Chile: Alberto Hurtado y Metales Pesados editores, 2014, p. 113-142.

ALISTE, E. y NÚÑEZ. A. Las fronteras del discurso geográfico: el tiempo y el espacio en la investigación social. Chungará, 2015, Vol. 47, № 42, p. 287-301.

ARAYA, B. El gran reportaje de Aisén. Coyhaique: GORE Aysén, 1998.

BACHELARD, G. La Poética del Espacio. México D.F.: Fondo de Cultura Económica, 2010.

BAEZA, B. Fronteras e identidades en Patagonia central (1885-2007). Rosario: PROHISTORIA Ediciones, 2009.

BAEZA, B. ¿Qué es argentino en la frontera patagónica? ¿Qué es chileno en la frontera patagónica? Una discusión en torno a los límites y marcos de la argentinidad y la chilenidad. Estudios Trasandinos, 2008, Vol. 14, Nº 1, p. 65-90.

BAEZA, B. "Patriotas" y extranjeros en la frontera de Patagonia Central chileno-argentina. El caso de Trevelin (Argentina) y Futaleufú (Chile). Si Somos americanos. Revista de Estudios Transfronterizos, 2011, Volumen XI, No 1, p. 41-62.

BAILLY, A.; SALAZAR, A. y NUÑEZ, A. Viaje por la Geografía. Una geografía para el mundo. Una geografía para todo el mundo. Santiago de Chile: Santiago de Chile: Serie GEOlibros, Instituto de Geografía, Pontificia Universidad Católica de Chile/RIL Editores, 2017.

BHABHA, H. (compilador). Nación y narración. Entre la ilusión de una identidad y las diferencias culturales. Buenos Aires: Siglo XXI editores, 2010. 
BHABHA, H. El lugar de la cultura. Buenos Aires: Manantial, 2011.

BHABHA, H. Nuevas minorías, nuevos derechos. Buenos Aires: Siglo XXI, 2013.

BELLO, A. Nampülkafe. El viaje de los mapuches de la Araucanía a las pampas argentinas. Territorio, política y cultura en los siglos XIX y XX. Temuco: Ediciones UC Temuco, 2011.

BENEDETTI, A. y LAGUADO, I. El espacio fronterizo argentino-chileno. Definición de categorías operativas y primera aproximación descriptiva. En: NÚÑEZ, A.; ARENAS, F. y SÁNCHEZ, R. (editores). Fronteras en movimiento e imaginarios geográficos. La cordillera de Los Andes como espacialidad sociocultural. Santiago de Chile: Serie GEOlibros, Instituto de Geografía, Pontificia Universidad Católica de Chile/RIL editores, 2013, p. 415-483.

BENWELL, M.C. Connecting Southern Frontiers: Argentina, the South West Atlantic and 'Argentine Antarctic Territory'. In: POWELL, R. \& DODDS, K. Polar Geopolitics? Knowledges, Resources and Legal Regimes. Cheltenham: Edward Elgar, 2014, p. 201-218.

BENWELL, M.C. Reframing Memory in the School Classroom: Remembering the Malvinas War. Journal of Latin American Studies, 2016, Vol. 48, № 2, p. 273-300.

BENWELL, M.C. Argentine territorial nationalism in the South Atlantic and Antarctica. In: DODDS, K.; HEMMINGS, A. \& ROBERTS, P. (editors). Handbook on the Politics of Antarctica. Cheltenham: Edward Elgar, 2017, p. 540-554.

CARRASCO, P. Relatos Orales, Rastros de la Identidad de la Patagonia Aysén. En: NUÑEZ, A.; ALISTE, E.; BELLO, A. y OSORIO, M. Imaginarios Geográficos, Prácticas y Discursos de Frontera: Aisén desde el texto de la nación. Santiago de Chile/Coyhaique Serie GEOlibros, Instituto de Geografía, Pontificia Universidad Católica de Chile/Ñire Editores, 2017, p. 92-107.

CRESSWELL, T. Space and Place (1977): Yi-Fu Tuan. In: HUBBARD, P.; KITCHIN, R. \& VALENTINE, G. Key text in Human Geography. London: Sage, 2008, p. 53-59.

DARDEL, E. Hombre y La Tierra. La Naturaleza de la realidad geográfica. Madrid: Biblioteca Nueva, 2013.

DE CERTEAU, M. La invención de lo cotidiano. México D.F.: Universidad iberoamericana, 2000.

ESCOBAR, A. La invención del Tercer Mundo. Construcción y deconstrucción del desarrollo. Santa Fe de Bogotá: Grupo Editorial Norma, 1998.

ESCOLAR, D. El sueño de la razón y los monstruos de la nación: la naturalización de Los Andes en la articulación estatal-nacional argentino-chilena. En: NUÑEZ, A.; SANCHEZ, R.; ARENAS, F. (editores). Fronteras en movimiento e imaginarios geográficos. La cordillera de Los Andes como espacialidad sociocultural. Santiago de Chile: Serie GEOlibros, Instituto de Geografía, Pontificia Universidad Católica de Chile/RIL editores, 2013, p. 91-112.

GIANNINI, H. La reflexión cotidiana. Hacia una arqueología dela experiencia. Santiago de Chile: Editorial Universitaria, 1995. 
GRIMSON, A. Los límites de la cultura. Crítica de las teorías de la identidad. Buenos Aires: Siglo XXI Editores, 2011.

HEIDEGGER, M. Construir, habitar, pensar. Conferencias y artículos. Barcelona: Ediciones del Serbal, 1994.

IVANOFF, D. La guerra de Chile Chico o los sucesos del lago Buenos Aires. Santiago de Chile, LOM, 2014.

IVANOFF, D. Los hijos de Aysén. Coyhaique: Mira Editores, 2011.

LEFEBVRE, H. La producción social del espacio. Madrid: Capitán Swing, 2013.

MARTINIC, M. De la Trapananda al Aysén. Coyhaique: Ediciones Fundación Río Baker, 2014.

MASSEY, D. Un sentido global del lugar. En: ALBET, A. y BENACH, N. Doreen Massey, un sentido global del lugar. Barcelona: Icaria, 2012, p. 112-129.

MASSEY, D. For Space. London: Sage, 2005.

MOLINA, R., Reconstrucción de los Etno-territorios. En: Tierra, Territorio y Desarrollo Indígena. Temuco: Institutos de Estudios Indígenas, Universidad de La Frontera, 1995.

NAVARRO FLORIA, P. (coordinador). Paisajes del progreso. La re-significación de la Patagonia Norte, 1880-1916. Neuquén: Centro de Estudios Patagónicos, Universidad Nacional de Comahue, 2007.

NÚÑEZ, A.; SÁNCHEZ, R. y ARENAS, F. (editores). Fronteras en movimiento e imaginarios geográficos. La cordillera de Los Andes como espacialidad sociocultural. Santiago de Chile: Geolibros-Instituto de Geografía, Pontificia Universidad Católica de Chile y RIL Editores, 2013.

NUÑEZ, A.; MOLINA, R.; ALISTE, E. y BELLO, A. Silencios geográficos en Patagonia-Aysén: territorio, nomadismo y perspectivas para re-pensar los márgenes de la nación en el siglo XIX. Magallania, 2016, Vol. 44, № 2. Disponible en Internet:

http://www.scielo.cl/scielo.php?script=sci_arttext\&pid=S0718-22442016000200006\&lng=es\&nr$m=i s o \& t$ lng $=e s$

NUÑEZ, A.; SÁNCHEZ, R. y ARENAS, F. De la montaña geográfica a las geografías de montaña. Un análisis de Los Andes chileno desde la geografía social. Journal of Alpine Research, 2017a (en prensa).

NUÑEZ, A.; ALISTE, E. y ARENA, F. Paisajes en fuga. Imaginarios y arquitecturas geográficas de la Patagonia. Revista AUS, 2017b (en prensa).

OSORIO, M. Antiguas historias del valle Simpson. Aysén: Ediciones Ñire Negro, 2013.

POMAR, J. La concesión del Aisén y el vale Simpson. Santiago de Chile: Imprenta Cervantes, 1923. 
QUIJANO, A. Colonialidad del poder, eurocentrismo y América Latina. En: LANDER, E. (compilador). La colonialidad del saber: eurocentrismo y ciencias sociales. Perspectivas Latinoamericanas. Buenos Aires: CLACSO, Argentina, 2009, p. 246-265.

SAAVEDRA, G. Paso al Sur: el litoral norte de Aysén: poblamiento, etnografía y desarrollo. Santiago de Chile: Memoria de título para optar al grado de Antropólogo social, Universidad de Chile, 2002.

SAAVEDRA, G. y NAVARRO, M. El Sur-austral en movimiento: Itinerarios chilotes en Patagonia insular occidental. En: KOTTOW, A. y TRAVERSO, A. (editores). Diálogos culturales/Imaginarios nacionales: Viajes, territorios e identidades. Santiago de Chile: RIL, 2016, p. 139-157.

SAID, E. Orientalismo. Barcelona: Editorial Debate, 2002.

SAHLINS, M. Las sociedades tribales. Barcelona: Ediciones Labor, 1972.

SPEDDING PALLET, A. Descolonización. Crítica y problematización a partir del contexto boliviano. La Paz: Instituto Superior Ecuménico Andino de Teología - ISEAT, 2011.

THER, F. Antropología del territorio. Polis, 2012, Vol. 11, № 32, p. 492-510.

TUAN, Y.F. Place: an experiential perspective. The Geographical Review, 1975, Vol. LXV, № 2, p. 151-165.

TUAN, Y.F. Topofilia. Un estudio de las percepciones, actitudes, y valores sobre el entorno. Madrid: Melusina, 2007.

ZUÑIGA, P. y NUÑEZ, A. Dibujando los márgenes de la nación: relatos y discursos de los viajeros-exploradores de Patagonia-Aysén entre los siglos XIX-XX. En: NUÑEZ, A.; ALISTE, E.; BELLO, A. y OSORIO, M. Imaginarios Geográficos, Prácticas y Discursos de Frontera: Aisén desde el texto de la nación. Santiago de Chile/Coyhaique Serie GEOlibros, Instituto de Geografía, Pontificia Universidad Católica de Chile/Ñire Editores, 2017, p. 45-62. 